\title{
Intravenous immunoglobulin therapy for asthma: time for a closer look?
}

\author{
C J Corrigan
}

The need for a pooled intravenous immunoglobulin preparation capable of passive transference of broad based humoral immunity was first recognised following the description of congenital agammaglobulinaemia by Bruton. It was subsequently recognised that this treatment, originally intended to restore immune deficiency, actually appeared to have therapeutic effects in diseases involving immune effector mechanisms, most notably "autoimmune" diseases such as immune thrombocytopenia. ${ }^{1}$ Intravenous immunoglobulin therapy is currently being evaluated for a possible therapeutic benefit in many other such diseases including rheumatoid arthritis, systemic lupus erythematosus, systemic vasculitis, myasthenia gravis, and others.

It is increasingly recognised that asthma is associated with chronic, cell-mediated inflammation of the bronchial mucosa in which cytokine products of activated $\mathrm{T}$ cells, especially those which are implicated in selective eosinophil accumulation, play a prominent role. Evidence suggests that glucocorticoids ameliorate asthma at least partly through inhibition of activated $\mathrm{T}$ cells and elaboration of their cytokine products. ${ }^{2}$ For this reason there has been interest in the investigation of other "anti-inflammatory" or "immunosuppressive" agents for their possible therapeutic benefits in asthma. Since many of these agents have potentially serious unwanted effects, attention has generally been focused on those asthmatic patients who continue to have severe disease despite properly administered, maximal topical glucocorticoid therapy and additional continuous systemic therapy. With such patients it is perceived that the benefits of amelioration of the disease and reduction or abolition of systemic glucocorticoid therapy, with its well recognised hazards, might outweigh the risks.

The possible efficacy of intravenous immunoglobulin therapy for asthma has been investigated in two open uncontrolled studies on children. Mazer and Gelfand ${ }^{3}$ treated eight children who required continuous systemic glucocorticoid therapy for asthma control with intravenous immunoglobulin in a dose of $1 \mathrm{~g} / \mathrm{kg}$ as a $6 \%$ solution on two consecutive days monthly for a total of six months (seven infusions). This regime was based on those used for the treatment of autoimmune diseases with intravenous immunoglobulin. Intravenous immunoglobulin therapy allowed alternate-day prednisone dosages, which were claimed to be the lowest possible for stable maintenance, to be reduced from $32.5 \mathrm{mg}$ to $11.5 \mathrm{mg}$. The mean forced expiratory volume in one second $\left(\mathrm{FEV}_{1}\right)$ - which was near normal anyway before treatment in most of the children and the concentration of methacholine provoking a fall in $\mathrm{FEV}_{1}$ of $20 \%\left(\mathrm{PC}_{20}\right)$ did not change significantly, although diary symptom scores and $\beta_{2}$ agonist usage were significantly reduced. The mean serum total $\mathrm{IgE}$ concentrations were slightly but significantly reduced, while mean serum IgG concentrations were increased from $5.85 \mathrm{~g} / 1$ before treatment to $12.4 \mathrm{~g} / 1$ four months after completion of the infusions. Unwanted effects of treatment were apparently too trivial to warrant specific documentation. The authors concluded that intravenous immunoglobulin therapy was associated with "clinical improvement, sparing of oral glucocorticoids and absence of drug-induced morbidity".

Less favourable conclusions were reached by Jakobsson and colleagues. ${ }^{4}$ They treated 14 adolescents requiring inhaled glucocorticoids (400-2000 $\mu$ g daily) to keep them "almost free from symptoms" - that is, requiring no more than two dosages of inhaled $\beta_{2}$ agonist daily. Owing to ethical constraints, the children were offered intravenous immunoglobulin therapy or entry to an untreated "reference" group in an open fashion. Nine patients who chose the treatment were commenced on intravenous immunoglobulin at an intended dosage of $1 \mathrm{~g} / \mathrm{kg}$ on a single day monthly for five months. Treatment with the high dosages used by Mazer and Gelfand was considered "too expensive". This dosage had to be decreased to $0.5 \mathrm{~g} / \mathrm{kg}$ after the first infusion because it caused severe headache, and then progressively increased (mean dosage $0.8 \mathrm{~g} / \mathrm{kg}$ ). Even at these lower dosages, infusions were frequently accompanied by fever and rigors. During the infusion period six patients were able to reduce dosages of inhaled glucocorticoid (from a mean of $720 \mu \mathrm{g} /$ day to $400 \mu \mathrm{g} /$ day) whereas three were not. Histamine bronchial reactivity was also reduced (mean $\mathrm{PC}_{20} 0.33-1.23 \mathrm{mg} / \mathrm{ml}$ ), as were total symptom scores. These differences, by comparison with the "reference" group, were not maintained after 10 additional months of follow up. Mean serum IgG concentrations before $(11.6 \mathrm{~g} / \mathrm{l})$ and four months after $(11.4 \mathrm{~g} / \mathrm{l})$ the infusions were almost identical, as were serum total $\operatorname{IgE}$ concentrations. In addition, serum concentrations of IgG anti-IgE antibodies and eosinophil cationic protein were unchanged. These authors concluded that the effects of intravenous immunoglobulin therapy were "small and temporary, and the treatment complicated and expensive". They also hypothesised that some of the improvement observed in the study of Mazer and Gelfand might have reflected the effects of immunoglobulin replacement, since they considered the mean serum IgG concentration before treatment in these children $(5.85 \mathrm{~g} / \mathrm{l})$ to be abnormally low, and a beneficial effect of intravenous immunoglobulin therapy had previously been demonstrated in asthmatic children with hypogammaglobulinaemia. ${ }^{5}$

A further open study of the effects of intravenous immunoglobulin therapy in two severe glucocorticoiddependent adult asthmatic patients is reported in this issue of Thorax. ${ }^{6}$ These patients were labelled "glucocorticoid insensitive" since they had severe airways obstruction (with high spontaneous variability) despite high dosages of systemic glucocorticoids with a poor clinical response to further escalation of therapy. In addition, peripheral blood $\mathrm{T}$ cells from these patients were said to show "decreased sensitivity" to dexamethasone in vitro. ${ }^{7}$ Treatment of both patients with intravenous immunoglobulin $(2 \mathrm{~g} / \mathrm{kg}$ on a single day monthly on four or six occasions) allowed a marked reduction in the dose of oral glucocorticoids accompanied by improvements in $\mathrm{FEV}_{1}$ and variability of PEF. In one of these patients bronchial biopsy specimens taken before and after four doses of intravenous immunoglobulin showed reductions in the numbers of $\mathrm{T}$ cells and cells expressing the $\mathrm{T}$ cell activation marker CD25 in 
the bronchial mucosa, while flow cytometric analysis of peripheral blood $\mathrm{T}$ cells showed reductions in the percentages of both CD4 and CD8 cells expressing the activation markers CD25 and HLA-DR. The serum concentration of total $\mathrm{IgE}$ was reduced, while that of total IgG was increased. In addition, these authors showed increased binding of the cytokine IL-8 to IgG autoantibodies in the serum of this patient following treatment. The serum concentration of eosinophil cationic protein was also reduced. Again, unwanted effects of therapy were presumably sufficiently mild as not to merit specific documentation.

How might intravenous immunoglobulin exert an antiasthma effect? Mazer and Gelfand ${ }^{3}$ postulated that intravenous immunoglobulin therapy might represent a form of passive immunotherapy, interfering with IgE-mediated reactions. ${ }^{8}$ In support of this, both they and Jakobsson and colleagues ${ }^{4}$ demonstrated reduced immediate skin prick test reactivity to a variety of allergens in their patients following intravenous immunoglobulin therapy, although this was not accompanied by RAST inhibition in vitro ${ }^{3}$ or evidence of increased binding of circulating IgE to IgG autoantibodies. ${ }^{4}$ The mechanism of this phenomenon, as well as its possible relevance to amelioration of asthma, therefore remains obscure. Intravenous immunoglobulin has been shown to abrogate activation of both $\mathrm{T}$ and $\mathrm{B}$ cells in vitro. ${ }^{910}$ Furthermore, soluble CD4, CD8, and HLA molecules have been identified in intravenous immunoglobulin preparations $\mathrm{s}^{11}$ which may act to inhibit presentation of antigen to $\mathrm{T}$ cells. Circumstantial evidence for inhibition of $\mathrm{T}$ cell activation by intravenous immunoglobulin in vivo has been provided by the present study of Vrugt and colleagues, although it would be unwise to infer a "cause and effect" relationship with asthma amelioration from observations on a single patient. Finally, this study raises the interesting possibility that intravenous immunoglobulin preparations might contain cytokine autoantibodies, which might inhibit the activities of these cytokines on inflammatory effector cells such as eosinophils.
It is self-evident that uncontrolled, open label studies such as those discussed here are impossible to interpret since they do not allow for the power of the placebo effect and take no account of spontaneous variability in asthma severity. Furthermore, little is known about possible spontaneous temporal variability of inflammatory cell numbers and their activation states in the peripheral blood and bronchial mucosa of asthmatic subjects. Nevertheless, these studies arguably justify the need for larger placebo controlled trials of the possible benefits of intravenous immunoglobulin therapy in glucocorticoid dependent asthma. It is to be hoped that the cost of such trials does not prove prohibitive.

Charing Cross and Westminster Medical School, London W6 8RF, UK

C J CORRIGAN

1 Bussel JB, Szatrowski TP. Uses of intravenous gammaglobulin in immune haematologic disease. Immunol Invest 1995;24:451-6.

2 Corrigan CJ, Haczku A, Gemou-Engesaeth V, Doi S, Kikuchi Y, Takatsu $\mathrm{K}$, et al. CD4 $\mathrm{T}$ lymphocyte activation in asthma is accompanied by increased serum concentrations of interleukin-5: effect of glucocorticoid therapy. Am Rev Respir Dis 1993;147:540-7.

3 Mazer BD, Gelfand EW. An open-label study of high-dose intravenous immunoglobulin in severe childhood asthma. $\mathcal{F}$ Allergy Clin Immunol 1991 87:976-83.

4 Jakobsson T, Croner S, Kjellman N-IM, Pettersson A, Vassella C, Björkstén B. Slight steroid-sparing effect of intravenous immunoglobulin in children and adolescents with moderately severe bronchial asthma. Allergy 1994; 49:413-20.

5 Page R, Friday G, Stillwagon P, Skoner D, Caliguiri L, Fireman P. Asthma and selective immunoglobulin subclass deficiency: improvement of asthma after immunoglobulin replacement therapy. F Pediatr 1988;112:127-31.

6 Vrugt B, Wilson S, van Velzen E, Bron A, Shute JK, Holgate ST, et al. Effects of high dose intravenous immunoglobulin in two severe corticosteroid insensitive asthmatic patients. Thorax 1997;52:662-4

Corrigan CJ, Brown P, Barnes NC, Szefler SJ, Tsai JJ, Frew AJ, et al. Glucocorticoid resistance in chronic asthma. Glucocorticoid pharmacokinetics, receptor characteristics, and inhibition of peripheral blood $T$ cell proliferation by glucocorticoids in vitro. Am Rev Respir Dis 1991; 144:1016-25

8 Blaser K, de Weck AL. Regulation of the IgE antibody response by idiotypeanti-idiotype network. Prog Allergy 1982;32:203-64.

9 Stohl W. Cellular mechanisms in the in vitro inhibition of pokeweed mitogeninduced B cell differentiation by immunoglobulin for intravenous use. $\mathscr{F}$ Immunol 1986;126:4407-13.

10 Kawada K, Terasaki PI. Evidence for immunosuppression by high-dose gamma globulin. Exp Hematol 1987;15:133-6.

11 Blasczyk R, Westhoff U, Grosse-Wilde M. Soluble CD4, CD8 and HLA molecules in commercial immunoglobulin preparations. Lancet 1993;341: 789-90. 